\title{
Properties of magnesium oxide boards used as sheathing in exterior walls
}

\author{
Stefanie Wøhler Nielsen ${ }^{1}$, Carsten Rode ${ }^{1, *}$, Tommy Bunch-Nielsen ${ }^{2}$, \\ Kurt Kielsgaard Hansen ${ }^{1}$, Wolfgang Kunther ${ }^{1}$, and Bent Grelk $^{1}$ \\ ${ }^{1}$ Technical University of Denmark, Lyngby, Denmark \\ ${ }^{2}$ Bunch Building Physics ApS, Vedbæk, Denmark
}

\begin{abstract}
Sheathing boards based on magnesium oxide (MgO) became very popular in the Danish market around the year 2010. However, it was realized a few years later that they condensed humidity from ambient air. The leakage from the boards led to severe problems with corrosion of metallic components and moisture uptake and degradation of wooden members. The boards have been banned from use in the Danish market since 2015, while damage cases valuing around 370 million EUR still need to be reconciled [1]. The binder in $\mathrm{MgO}$ board is formed by a chemical reaction between $\mathrm{MgO}$ and $\mathrm{MgCl}_{2}$. However, $\mathrm{MgSO}_{4}$ is a possible alternative to $\mathrm{MgCl}_{2}$, and such boards may have smaller moisture uptake, to reduce this issue. This paper gives an account of recent activities to compare properties of $\mathrm{MgO}$ boards, based on chlorides or sulphates. The investigations comprise: (1) Analysis of elemental composition and crystalline components, (2) Examination in optical microscope and scanning electron microscope, (3) Determination of moisture retention and water vapour permeability, (4) Analysis of chemical composition of leaked salt water from boards, and (5) Visual observation of decomposition and determination of dry mass change after exposure to high humidity.
\end{abstract}

\section{Introduction}

Around the year 2010, a new sheathing board product, the magnesium oxide (MgO) board, became a popular building material in Denmark to be used inside ventilated façades as sheathing behind a ventilated air gap. However, during winter 2015 Ingeniøren - the official magazine of the Engineering Association of Denmark - began reporting widespread moisture damage inside ventilated facades of Danish buildings constructed with $\mathrm{MgO}$ boards [2].

The binder in $\mathrm{MgO}$-boards is formed by a chemical reaction between $\mathrm{MgO}$ and $\mathrm{MgCl}_{2}$, which was first produced by Stanislas Sorel in 1867 and is known as Sorel cement or magnesium oxychloride cement. The product is hard and strong but decomposes over time by contact with water or air at high relative humidity [3].

An investigation of Danish buildings revealed that the $\mathrm{MgO}$-boards suffer from the same durability issue as its binder. When MgO-boards are exposed to high humidity, they

\footnotetext{
${ }^{*}$ Corresponding author: car@byg.dtu.dk
} 
absorb an excessive amount of moisture from the air and form water drops that contain a high amount of chloride ions. This process is also referred to as "crying" [4].

To improve the resistance to degradation of the product, $\mathrm{MgO}$-boards containing $\mathrm{MgSO}_{4}$ have been introduced to the market because of the less hygroscopic behaviour of magnesium sulphate compared to magnesium chloride [5]. The purpose of this paper is therefore to investigate the moisture properties of the different types of MgO-boards.

\section{Materials for investigation}

All investigations were performed on the same three $\mathrm{MgO}$-boards delivered by a Chinese manufacturer, where \#1 $(9 \mathrm{~mm})$ and \#2 $(12 \mathrm{~mm})$ are magnesium sulphate boards and \#3 $(12 \mathrm{~mm})$ is a magnesium chloride based board. The elemental composition of the MgOboards has been determined using both X-ray Fluorescence (XRF, Ameteks Spectro xSort $\mathrm{x}$-Ray Spectrometer) and Energy Dispersive X-ray (EDX, Jeol JSM-6510 with Bruker XFlash Detector 410-M). Both analyses were performed on a cross-section of the materials. The results are presented in Table 1 where the main difference is the chloride and sulphate content.

Table 1. XRF and EDX results of the MgO-boards. Note that oxygen and carbon cannot be included in the measurement. The rest has been scaled to $\%$ of mass and represent an approximation of the binder composition.

\begin{tabular}{|c|c|c|c|c|c|c|c|c|c|c|}
\hline & \multicolumn{5}{|c|}{ XRF results } & \multicolumn{5}{|c|}{ EDX results } \\
\hline & $\mathrm{Mg}$ & $\mathrm{Si}$ & $\mathrm{S}$ & $\mathrm{Cl}$ & $\mathrm{Ca}$ & $\mathrm{Mg}$ & $\mathrm{Si}$ & $\mathrm{S}$ & $\mathrm{Cl}$ & $\mathrm{Ca}$ \\
\hline$\# 1-\mathrm{MgSO}_{4} 9 \mathrm{~mm}$ & $73 \%$ & $10 \%$ & $13 \%$ & $2 \%$ & $2 \%$ & $84 \%$ & $5 \%$ & $9 \%$ & $0 \%$ & $1 \%$ \\
\hline$\# 2-\mathrm{MgSO}_{4} 12 \mathrm{~mm}$ & $79 \%$ & $6 \%$ & $12 \%$ & $2 \%$ & $2 \%$ & $80 \%$ & $8 \%$ & $10 \%$ & $0 \%$ & $2 \%$ \\
\hline$\# 3-\mathrm{MgCl}_{2} 12 \mathrm{~mm}$ & $68 \%$ & $9 \%$ & $1 \%$ & $21 \%$ & $2 \%$ & $77 \%$ & $2 \%$ & $0 \%$ & $19 \%$ & $1 \%$ \\
\hline
\end{tabular}

The crystalline components in the $\mathrm{MgO}$-boards have been identified qualitatively using powder X-ray Diffraction (XRD) on samples with grain sizes less than $200 \mu \mathrm{m}$ on the $X^{\prime}$ Pert PRO PANalytical device with measurements in steps of $0.001^{\circ}$ from $3^{\circ}$ to $65^{\circ}$. The peaks were identified based on the "ICDD PDF-2/Release 2009 RDB" database and the results are shown in Table 2. Several hydrate phases form in these binders, which are in agreement with Walling \& Provis [5]. $\mathrm{SiO}_{2}$ and $\mathrm{MgCO}_{3}$ are not hydration products and thus likely to originate from filler materials.

Table 2. Observed phases in the three MgO-boards using powder XRD.

\begin{tabular}{llcl}
\hline & Chemical Formula & Ref. Code (PDF) & Comments \\
\hline$\# 1-\mathrm{MgSO}_{4} 9 \mathrm{~mm}$ & $\mathrm{Mg}(\mathrm{OH})_{2}$ & $00-001-1169$ & \\
& $\mathrm{Mg}_{4}(\mathrm{OH})_{6} \mathrm{SO}_{4} \cdot 8 \mathrm{H}_{2} \mathrm{O}$ & $00-007-0418$ & Binders \\
& $\mathrm{Mg}_{6}(\mathrm{OH})_{10} \mathrm{SO}_{4} \cdot 3 \mathrm{H}_{2} \mathrm{O}$ & $00-007-0415$ & \\
\cline { 2 - 4 } & $\mathrm{MgCO}_{3}{ }^{* *}$ & $01-080-0042$ & \\
\cline { 2 - 4 } & $\mathrm{SiO}_{2}{ }^{* *}$ & $01-076-0940$ & \\
\hline$\# 2-\mathrm{MgSO}_{4} 12 \mathrm{~mm}$ & ${\mathrm{Mg}(\mathrm{OH})_{2}}$ & $00-001-1169$ & \\
& $\mathrm{Mg}_{4}(\mathrm{OH})_{6} \mathrm{SO}_{4} \cdot 8 \mathrm{H}_{2} \mathrm{O}$ & $00-007-0418$ & Binders \\
\cline { 2 - 5 } & $\mathrm{MgCO}_{3}{ }^{* *}$ & $01-080-0042$ & \\
\cline { 2 - 5 } & $\mathrm{SiO}_{2}{ }^{* *}$ & $01-076-0940$ & \\
\hline$\# 3-\mathrm{MgCl}_{2} 12 \mathrm{~mm}$ & $\mathrm{Mg}_{3}(\mathrm{OH})_{5} \mathrm{Cl} \cdot 4 \mathrm{H}_{2} \mathrm{O}$ & $00-007-0420$ & Binder \\
\cline { 2 - 4 } & $\mathrm{Mg}_{6} \mathrm{Al}_{2}\left(\mathrm{CO}_{3}\right)(\mathrm{OH})_{16} \cdot 4 \mathrm{H}_{2} \mathrm{O}$ & $00-054-1029$ & \\
\hline
\end{tabular}

Small quantities. 


\section{Microstructure analysis of MgO-boards}

For the microstructural analysis of the boards, an optical microscope with plane- and crossed polarized light was used. The analysis revealed a high content of air in both types of MgO-boards. Furthermore, many different filler materials are present, of which some are highly porous, and perlite is most likely one. See Figure 1.
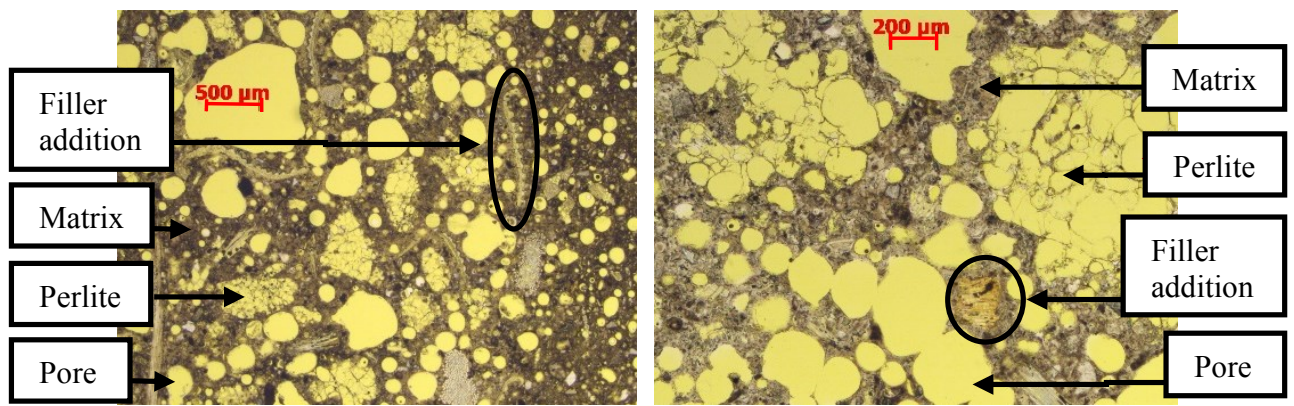

Fig. 1. Left picture: Specimen \#1 - $\mathrm{MgSO}_{4} 9 \mathrm{~mm}$. Right picture: Specimen \#3- $\mathrm{MgCl}_{2} 12 \mathrm{~mm}$.

The specimens were further analysed using Scanning Electron Microscopy (SEM) with EDX in backscattered electron mode (BSE) with an FEI Quanta 200 ESEM microscope and an acceleration voltage of $15 \mathrm{keV}$. The EDX maps were measured with an Oxford Instrument (OI) X-Max ${ }^{\mathrm{N}}$ detector and show that the matrix of the sulphate based boards consists of magnesium and sulphate with no visible content of chloride i.e. no contrast. Furthermore, the analysis revealed the matrix of the chloride based board to consist mostly of magnesium and chloride with no visible contrast for the sulphate. See Figure 2.
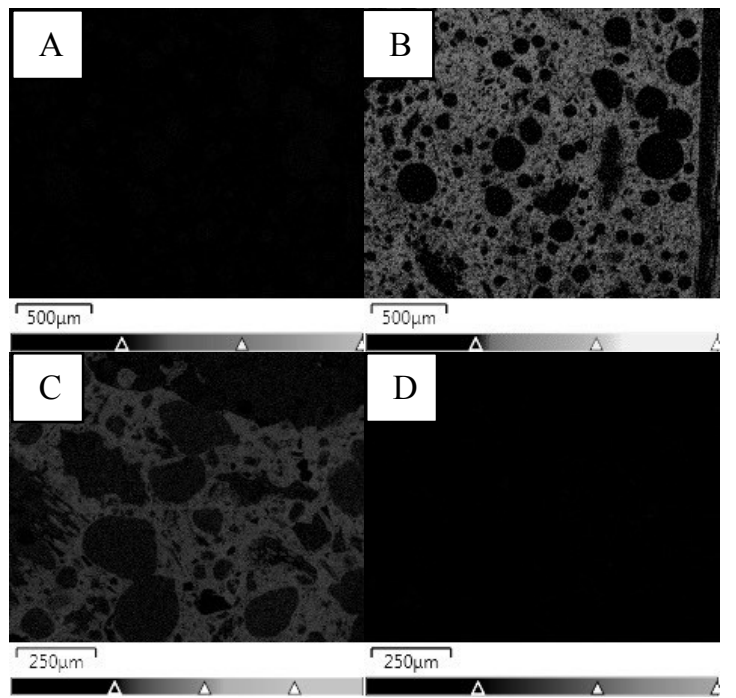

Fig. 2. Energy-Dispersive $\mathrm{X}$-ray spectroscopy (EDX) maps of (A) chloride and (B) sulphate in specimen \#1 - $\mathrm{MgSO}_{4} 9 \mathrm{~mm}$ and of (C) chloride and (D) sulphate in specimen \#3- $\mathrm{MgCl}_{2} 12 \mathrm{~mm}$.

\subsection{Qualitative evaluation of the volume percent composition}

A quantitative evaluation of the volume percent composition was performed by counting a total of 1000 points per specimen at 50 times magnification through an ocular grid plate. 
The data derived showed significant changes in the volume percentage up until 500 points, indicating the samples to be highly inhomogeneous. The results are presented in Table 3.

Table 3. Volume percentage of (1) air, (2) organic filler additions and perlite, and (3) the matrix.

\begin{tabular}{lccc}
\hline & Air & Organic + perlite & Matrix \\
\hline$\# 1-\mathrm{MgSO}_{4} 9 \mathrm{~mm}$ & $15 \%$ & $15 \%$ & $70 \%$ \\
$\# 2-\mathrm{MgSO}_{4} 12 \mathrm{~mm}$ & $20 \%$ & $15 \%$ & $65 \%$ \\
$\# 3-\mathrm{MgCl}_{2} 12 \mathrm{~mm}$ & $15 \%$ & $20 \%$ & $65 \%$ \\
\hline
\end{tabular}

\section{Moisture retention measurements on MgO-boards from air}

A moisture retention test was performed for seven weeks at $20{ }^{\circ} \mathrm{C}$ by placing samples of each $\mathrm{MgO}$-board in a climate chamber. Before starting the experiment, a dry mass of about $10 \mathrm{~g}$ was obtained by placing the samples in a heating chamber at $105^{\circ} \mathrm{C}$ for four days and cooled to room temperature in a desiccator. The samples were placed in petri glass dishes together with two watch glasses with the purpose of allowing ventilation and making it easy to observe any water drops forming underneath. The samples were then exposed to a relative humidity from $85 \%$ to $95 \%$ in steps of $2 \% \mathrm{RH}$.

Weightings were performed without opening the climate chamber by using a glove that is attached to the front door. Results from every step during the seven weeks are depicted in Figure 3 where the increase in mass is measured after seven days at all steps except $91 \%$ RH, which was kept for 14 days. Note that the boards are not in equilibrium with the humidity after seven days and would absorb more water given more time. Initial "tears" were observed on the chloride based board at $89 \% \mathrm{RH}$ after having gained $43 \%$ in mass and mould growth was observed on it at $93 \% \mathrm{RH}$. The first sight of "tears" from the sulphate based boards was observed seven weeks into the experiment at $95 \% \mathrm{RH}$. At this point both sulphate based boards had gained around $60 \%$ in mass.

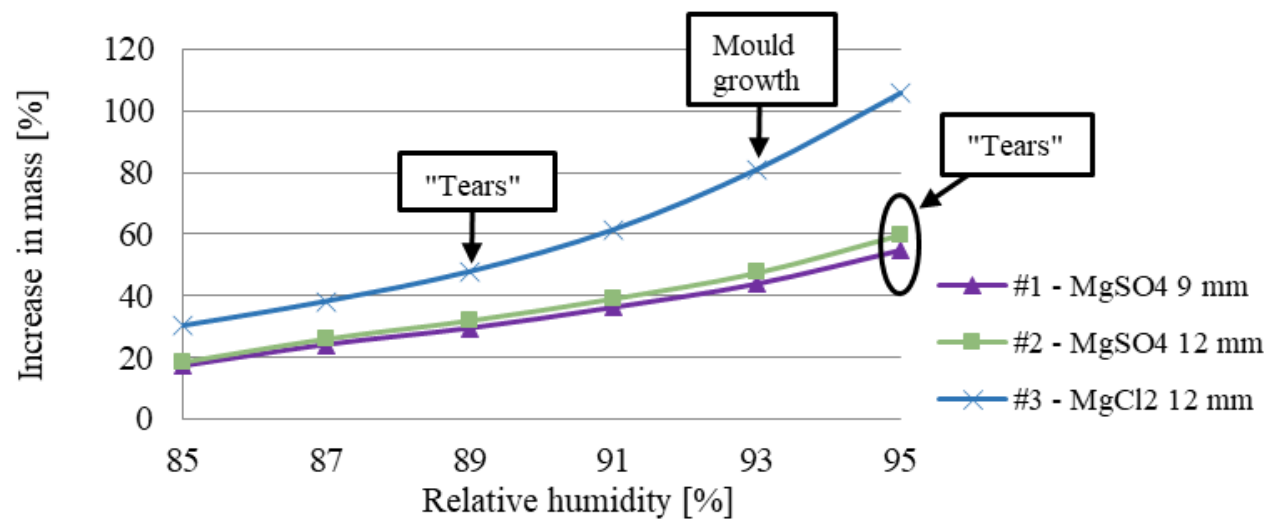

Fig. 3. Moisture retention curve from $85 \%$ RH to $95 \%$ RH measured over the course of seven weeks. The increase in mass includes the weight of "tears".

The amount of "tears" and mould growth that had appeared on the chloride based board at the end of the moisture retention test can be seen in Figure 4 together with a picture of one of the sulphate based boards, which was kept at $95 \% \mathrm{RH}$ for two additional weeks after the moisture retention test was over. The amount of "tears" and mould growth on the sulphate based boards was significantly less than that of the chloride based. 

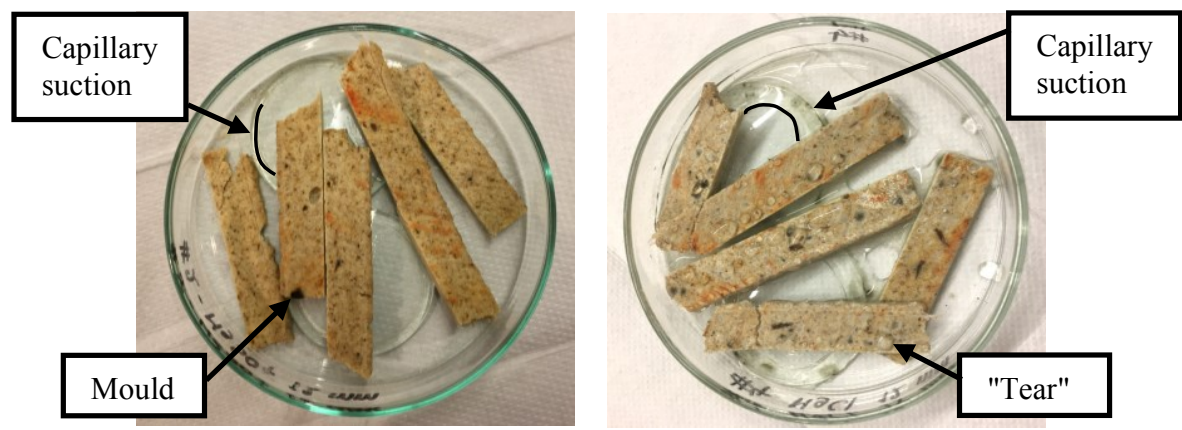

Fig. 4. Left picture: Sample $\# 2-\mathrm{MgSO}_{4} 12 \mathrm{~mm}$ after nine weeks of exposure to high humidity. Right picture: Sample \#3- $\mathrm{MgCl}_{2} 12 \mathrm{~mm}$ after seven weeks of exposure to high humidity.

\section{Water vapour resistance for MgO-boards}

The water vapour resistance $Z_{p}$ of the MgO-boards has been measured by using the 'wet cup' test described in EN 12572 with conditions of 50/93\% RH and are presented in Table 4 along with the water vapour permeability $\delta_{p}$ [6]. The measured water vapour resistances are similar to the water vapour resistance of a $6 \mathrm{~mm}$ fibre cement board [7].

Table 4. Water vapour resistance $Z_{p}$ and water vapour permeability $\delta_{p}$.

\begin{tabular}{lcc}
\hline & $\begin{array}{c}\text { Water vapour resistance, } Z_{p} \\
{\left[\mathrm{GPa} \cdot \mathrm{m}^{2} \cdot \mathrm{s} / \mathrm{kg}\right]}\end{array}$ & $\begin{array}{c}\text { Water vapour permability, } \delta_{p} \\
\times 10^{-12}[\mathrm{~kg} /(\mathrm{Pa} \cdot \mathrm{m} \cdot \mathrm{s})]\end{array}$ \\
\hline$\# 1-\mathrm{MgSO}_{4} 9 \mathrm{~mm}$ & $2.4 \pm 0.2$ & $3.7 \pm 0.3$ \\
$\# 2-\mathrm{MgSO}_{4} 12 \mathrm{~mm}$ & $4.4 \pm 0.3$ & $2.8 \pm 0.2$ \\
$\# 3-\mathrm{MgCl}_{2} 12 \mathrm{~mm}$ & $2.9 \pm 0.4$ & $4.1 \pm 0.5$ \\
\hline
\end{tabular}

\section{Chemical composition of leaked salt water from MgO-boards}

At the end of the moisture retention test, "tears" were collected from the samples and an analysis of them was done using Inductively Coupled Plasma Optical Emission Spectrometry and Ion Chromatograph equipment. The results are presented in Table 5. For comparison, in can be informed that the Atlantic ocean contains $20000 \mathrm{Cl}^{-} \mathrm{mg} /$ liter [3].

Table 5. Results of ions found in "tear" drops from MgO-boards given in $\mathrm{mg} / \mathrm{liter}$.

\begin{tabular}{lllllll}
\hline & $\mathrm{Na}^{+}$ & $\mathrm{Mg}^{++}$ & $\mathrm{S}^{--}$ & $\mathrm{Cl}^{-}$ & $\mathrm{K}^{+}$ & $\mathrm{Ca}^{++}$ \\
\hline$\# 1-\mathrm{MgSO}_{4} 9 \mathrm{~mm}$ & 413 & 27794 & 36172 & 1490 & 269 & 323 \\
$\# 2-\mathrm{MgSO}_{4} 12 \mathrm{~mm}$ & 406 & 28099 & 34721 & 1227 & 153 & 291 \\
$\# 3-\mathrm{MgCl}_{2} 12 \mathrm{~mm}$ & 540 & 14053 & 753 & 44123 & 322 & 0 \\
\hline
\end{tabular}

\section{Visual observations and dry mass change after exposure to high humidity}

The MgO-boards cannot be distinguished from each other by eye at time of delivery, as they are all the same shade of white. After one day at $85 \% \mathrm{RH}$, the chloride based board changed into a brownish colour, while the sulphate based boards turned brown after four weeks of exposure to a relative humidity between $85 \%$ and $91 \% \mathrm{RH}$. 
After having collected "tears" from the samples, a new dry mass was measured by placing the samples in an oven at $105^{\circ} \mathrm{C}$ for four days and cooled to room temperature in a glass desiccator containing silica gel. When drying the boards, they once again turned white. The difference in dry mass for each sample is given in Table 6.

Table 6. Results of mass change relative to dry mass before moisture exposure.

\begin{tabular}{cccc}
\hline & $\# 1-\mathrm{MgSO}_{4} 9 \mathrm{~mm}$ & $\# 2-\mathrm{MgSO}_{4} 12 \mathrm{~mm}$ & $\# 3-\mathrm{MgCl}_{2} 12 \mathrm{~mm}$ \\
\hline Mass change & $+7 \%$ & $+8 \%$ & $-0.7 \%$ \\
\hline
\end{tabular}

\section{Discussion}

The moisture retention measurements indicate the sulphate based boards to condense less water than the chloride based board tested when exposed to a high relative humidity. However, the $\mathrm{MgSO}_{4}$-boards did start to "cry" at a relative humidity of $95 \%$ and the mass increased significantly at lower relative humidity - e.g. at outdoor RH levels which are common in a country such as Denmark. The obtained moisture properties of the sulphate based boards support references stating that magnesium oxysulphate cement suffers from susceptibility to degradation when exposed to moisture [5].

\section{Conclusions}

Based on the results, it can be concluded that both types of MgO-boards have an ability to absorb unacceptable amounts of water from a humid ambient, although the MgO-boards based on sulphate do condense less water from the environment than the $\mathrm{MgO}$-board based on chloride when exposed to a high relative humidity. Thus, $\mathrm{MgSO}_{4}$ is not a possible alternative that should be used in Denmark and countries with a similar humid climate.

\section{References}

1. U. Andersen, Ingeniøren, Efter ny MgO-kendelse: MT Højgaard henscetter 400 mio. $\mathrm{kr}$. til erstatninger (2018). Retrieved February 13, 2019, from https://ing.dk/artikel/efterny-mgo-kendelse-mt-hoejgaard-hensaetter-400-mio-kr-erstatninger-214490

2. U. Andersen, Ingeniøren, Dyrt slagsmål om vindspcerreplader på vej (2015). Retrieved February 13, 2019, from https://ing.dk/artikel/dyrt-slagsmaal-om-vindspaerrepladerpaa-vej-174712

3. A. Herholdt et al, Aalborg Portland, The Concrete-Book 2nd ed (1985).

4. K.H. Kielsgaard, T. Bunch-Nielsen, B. Grelk, C. Rode, International RILEM Conference on Materials, Systems and Structures in Civil Engineering, MagnesiumOxide Boards Cause Moisture Damage Inside Facades in New Danish Buildings (2016).

5. S.A. Walling, J.L. Provis, Chem. Rev., Magnesia-Based Cements: A Journey of 150 Years, and Cements for the Future?, 116, 4170-4204 (2016).

6. European Committee for Standardization, Danish Standard Association, DS/EN 12572 Hygrothermal performance of building materials and products - Determination of water vapour transmission properties (2001).

7. E. Brandt et al, Danish Building Research Institute, Aalborg University Copenhagen, SBi-direction 224: Moisture in building 2nd ed. (2013). 